\title{
Multilingual Medieval Sermons: Sources, Theories and Methods
}

\section{Jan Odstrčilík*}

Multilingualism, i.e. the ability of a speaker or a group of speakers to use two or more languages $^{1}$ has to be regarded as one of the most characteristic features of medieval societies. In those parts of Europe in which Latin Christianity prevailed during the Early Middle Ages and to which the contributions collected in this cluster are devoted, the languages simultaneously used in daily life, politics, commercial intercourse, religious communication, and higher education were always and everywhere more than one: Latin and the one or more vernacular languages that were prevalent in the respective area. This corresponds to the fact that the majority of European polities were inhabited by people of various vernacular languages who lived together in cities, in cloisters, at the courts of the individual power holders, as well as in the countryside. Around individual languages powerful identity narratives were formulated, strategies of distinction educed, and discourses of translation formed, discussed and transformed. We may say that these languages, their interactions, mutual interferences, and the theoretical and methodological reasoning accompanying their use formed the self-understanding of European societies. Here a specific role was played by the varying prestige of individual languages. The relationship between Latin as a language of liturgy and scholarship, and the individual vernacular languages used in daily communication, politics, and commerce caused permanent tensions which we may observe in a great range of written sources.

Despite the great importance of medieval multilingualism for our understanding of medieval societies and despite pertinent textual sources mirroring multilingual cultural practices, the respective research was rather selective for a long time and the most distinctive group of written sources available - the multilingual medieval sermons - was only modestly studied. This has changed rapidly in the last twenty five years, and the research devoted to them can now be described as a very dynamic field of study. ${ }^{2}$ Preaching was arguably the most important mass medium of the European Middle Ages. ${ }^{3}$ The textual witnesses of the preaching, especially the multilingual sermons, are sometimes considered as a link to the spoken word of the past. ${ }^{4}$ However, this is more complicated: the absolute majority of

* Correspondence details: Jan Odstrčilík, Institute for Medieval Research, Austrian Academy of Sciences, Hollandstraße 11-13, 1020 Vienna, Austria; email: Jan.Odstrcilik@oeaw.ac.at.

1 There are various other definitions of multilingualism. Some of them view bilingualism as an ability to speak two languages and multilingualism as an ability to speak more than two. Others view bilingualism as an individual ability while multilingualism as a characteristic of a society. Here, bilingualism is understood as a specific case of multilingualism involving only two languages. See Cenoz, Defining multilingualism, 7.

2 The study by Siegfried Wenzel, Macaronic Sermons, from 1994, which will be discussed later in this introduction, may be rightfully understood as the beginning of the modern study of medieval multilingual sermons.

3 See, e.g., D’Avray, Preaching of the Friars, 3-4.

4 Kämmerer, Codeswitching in Predigten, 34. 
extant sermon production cannot be regarded as direct records of delivered sermons and many of them were, indeed, intended for reading. ${ }^{5}$ Nevertheless, they still offer excellent material for study. They feature an astounding plethora of forms and types of medieval written multilingualism: vernacular glosses accompanying Latin text, written by authors, copyists and readers; Latin texts containing interlinear and/or marginal translations in one or two vernaculars; bilingual and trilingual texts in which Latin adopts syntactic, morphological and grammatical features of the respective vernacular, which may have then been regarded as the dominant language; and also texts showing fully fledged code-switching, which represents the most important topic of the research on multilingualism in general.

The majority of multilingual sermons ${ }^{6}$ have not yet been published, ${ }^{7}$ methodologies for dealing with the historical multilingualism are still being discussed and far from agreed upon. The respective research very often remains enclosed within national philologies, with only modest cross-disciplinary discussion and almost no comparative approaches considering material from unrelated linguistic areas with specific types of language mixing as well as difficult to compare cultural and historical traditions. We are confronted with this problem not only if attempting to compare European and non-European multilingualism, but also the multilingual practices within one and the same cultural area. For example, Czech insertions in a Latin sermon will differ from English insertions simply due to the fact that Czech is an inflected language, thus allowing for different combinations with Latin inflected forms, wherefore different methods have to be developed and applied for these sources.

Promoting an exchange between various national philologies and discussing theoretical and methodological approaches was the main endeavor of the workshop "Understanding Multilingual Sermons of the Middle Ages: Forms, Methodologies, and Challenges « that took place on 15th-17th May 2018 at the Austrian Academy of Sciences, ${ }^{8}$ one of the first events dedicated to this particular text type. The results of this workshop are now going to be presented in two subsequent clusters in the journal Medieval Worlds. The cluster presented in this issue comprises five essays on material originating from Ireland, England, France, Catalonia and Italy by Herbert Schendl, Tom ter Horst, Lidia Negoi, Carlo Delcorno and Nicole Bériou.

In the study of multilingual medieval sermons, there are currently two main approaches and one new one emerging. The first is based on traditional philological, codicological and paleographical text analysis as well as historical contextualization of the sources of interest. Critical editions of key multilingual texts are the immensely valuable result of this research, editions which represent an indispensable basis for further interdisciplinary research. In the present cluster, this philological approach is represented mainly by Nicole Bériou. She These sermons are also commonly called "macaronic sermons«, e.g., the monograph of Siegfried Wenzel Macaronic Sermons. The appropriateness of the term "macaronic « for this type of medieval text is discussed by Demo, Towards a unified definition.

7 The situation is slowly improving, cf. Horner, Macaronic Sermon Collection; Florianová et al., Quadragesimale Admontense.

8 overmode.oeaw.ac.at/sermons/. 
discusses reportationes - records of delivered sermons made by listeners, in her case medieval university students in Paris. The individual sermons were delivered mainly in the vernacular, i.e. French, but recorded in a mixture of Latin and French. Carlo Delcorno and Lidia Negoi based their respective analyses on philological description and historical contextualization, combining it with code-switching approaches.

The second major approach is the study of code-switching, from both sociolinguistic and syntactic (or structural) perspectives. Many of these methodologies play a role in the individual essays of this cluster. Sociolinguistic methods focus on social factors and motivators of code-switching and blend naturally with the traditional hermeneutical analysis of medieval texts. The syntactic perspective is, however, much more challenging for medievalists. It investigates circumstances under which code-switching occurs. Early research supposed that the switching between languages occurs at random, both in the case of inter- as well as intrasentential switching. Intrasentential switching is of eminent interest for linguists because only there are the grammatical structures in direct contact. The essays in this cluster concentrate for the most part on intrasentential switching too. In the late 1970 s and early 1980 s, Shana Poplack analysed the practice of code-swithing among bilingual Puerto Ricans in New York City ${ }^{9}$ and formulated the hypothesis that intrasentential switching is subject to grammatical constraints: the so-called free morpheme constraint and the equivalence constraint. According to the free morpheme constraint hypothesis, no switching can occur between a free morpheme and a bound morpheme. ${ }^{10}$ This means that the switch cannot occur, e.g., between the stem of the word and its suffix. The second rule is the equivalence constraint hypothesis. According to this, the switches occur only at points where the surface structures of the languages coincide, or between sentence elements that are normally ordered in the same way by each individual grammar. ${ }^{11}$

The universal applicability of both rules for modern code-switching was repeatedly denied in the recent research discussion because of the many examples which do not comply with these rules. ${ }^{12}$ This is also true for the historical code-switching. The free morpheme constraint is not applicable to highly artistic texts like the so-called macaronic poems from renaissance, which are often defined precisely by mixing vernacular stems with Latin endings. ${ }^{13}$ This shows not only the difference between spoken and written language but also the difference between artistic and "natural« language mixing. Macaronic poems from the renaissance are an extreme example, however; in the case of multilingual sermons, it is debated how much they reflect the "natural « bilingualism of their authors and readers, and how much they should be regarded as products of rhetorical education and practice.

9 Poplack, Sometimes I'll start.

10 Poplack, Sometimes I'll start, 585-586. The theory of free morpheme constraint was challenged, among others, by Azuma, Free morpheme constraint revisited, who proposes instead a constraint »based on the notion of semantic content".

11 Poplack, Sometimes I'll start, 586.

12 See Pfaff, Constraints on language mixing, who proposes four main types of constraints: functional, structural, semantic and discourse-related. Cf. Woolford's generative model of code-switching: Woolford, Bilingual code switching (all approaches based on data of spoken languages from Spanish-English bilinguals).

13 So-called lexical hybridization, see Demo, Towards a unified definition, 86-87. 
Another influential theory, Myers-Scotton's "Matrix Language Frame«, postulates that one of the languages provides the grammatical frame into which pockets of the other (embedded language) are inserted. ${ }^{14}$ The theories on constraints and on the matrix and embedded language are joined in the concepts of insertion, alternation and congruent lexicalization proposed by Pieter Muysken. Insertion corresponds to Myers-Scotton's concept of a matrix structure, into which elements of another language are inserted; alternation corresponds to Poplack's equivalency constraint, which requires compatible syntactical structures for code-switching; and finally, congruent lexicalization refers to a situation in which two languages (or varieties of one language like a dialect/standard) share the same grammatical structure that can be filled by lexical elements from one language or another. ${ }^{15}$ Muysken also uses the term »code-switching " exclusively for alternation. Otherwise, as a general term, he uses code-mixing. ${ }^{16}$

The bridge between the philological-historical and linguistic approach to code-switching in the written language of medieval sermons is represented by the groundbreaking monograph Macaronic Sermons by Siegfried Wenzel from 1994, which focused on multilingual sermons from medieval England. While recognizing the importance of code-switching, the analysis is firmly rooted in the traditional philological discourse. Wenzel classified elements of the vernacular language inserted into Latin, the main (matrix) language, into three types: "a«, »b« and "c« elements. Type »a includes translations of Latin words into the vernacular language, technical terms in Latin, translations of quotes, vernacular idioms or proverbs. Among "b « elements we find vernacular words, phrases, clauses, periods, or even paragraphs that fulfill the role of divisions, subdivisions or distinctions in the medieval sermons. They work as structural elements in the sermons, e.g., the division often appears first in Latin and is then translated into English. Words or parts of words which are integrated into the bilingual syntactical structures are classified as "c " elements. ${ }^{17}$ The plausibility of these categories may be disputed, as done by Herbert Schendl in his contribution on medieval English sermons to this cluster. Nevertheless, they represent an indispensable departure point for many analyses of medieval multilingualism, especially code-switching - thus contributing greatly to the field of study. In this cluster, Wenzel's methodological approach is applied by Carlo Delcorno in his study of the sermons of Angelo da Porta Sole (d. 1334). However, all our authors refer to Wenzel's work, e.g., Lidia Negoi discusses Catalan examples of vernacular divisions in a Latin text and uses the results to discuss Wenzel's approach. 
A more profound linguistic methodology following Wenzel's conceptualization has so far been developed mainly by scholars working with bilingual Latin-English sources, especially Herbert Schend $l^{18}$ in his numerous articles. However, recently, there is growing research on this material; see, for example, the publications by Helena Halmari and Timothy Regetz, ${ }^{19}$ or Mareike Keller. ${ }^{20}$ In recent years, Irish (Tom ter Horst ${ }^{21}$ and Nike Stam ${ }^{22}$ ), ${ }^{23}$ German, Spanish and Italian (studied by Carmen Kämmerer) ${ }^{24}$ textual material has become the focus of attention. In this cluster, this syntactical linguistic approach is represented by Tom ter Horst, who uses Muysken's typology to analyze English and Irish material. Moreover, selected examples are annotated using the generally accepted Leipzig Glossing Rules, ${ }^{25}$ thus making them understandable for a broader academic audience.

The main issue in the scholarly discussion on the code-switching evidenced in medieval texts is the applicability of linguistic methodologies developed on spoken language. We usually do not know how and by whom our source texts were created, and especially what were the linguistic competences of these, often anonymous, authors: at which level in the process of transcription multilingual elements entered the transmitted text and for what purpose. Alan Fletcher argued that multilingual sermons were intended for reading. ${ }^{26}$ Moreover, on the rare occasions in which there is more than one version of a particular multilingual sermon preserved, we can observe remarkable differences concerning the multilingual elements. Nicole Bériou has shown in her work on reportationes that the histories of transmission of multilingual textual elements are far from straightforward and that large differences are observable at various stages of reception. Some multilingual elements disappear and new ones appear at various stages of the reception of one and the same text. ${ }^{27} \mathrm{My}$ own research on Latin-Czech texts shows similar results. The so-called Bethlehem sermons, probably partly based on reportationes of sermons delivered by the reform theologian Jan Hus, contain different versions of one and the same text. ${ }^{28}$ Many extant multilingual sermons are without doubt based on translations, as is the case for Latin-German sermons studied by Hans-Jochen Schiewer and Regina Schiewer. ${ }^{29}$ In my analysis of Latin translations of Czech sermons written by Jan Hus and directed to readers, I have pointed out the fact that despite being a word-for-word translation, they still feature many "a « and "c« elements which are

E.g., Code-switching; Syntactic constraints; English historical code-switching, and many others.

Halmari and Regetz, Syntactic aspects of code-switching.

Keller, Code-Switching.

Ter Horst, Codeswitching.

More precisely, a multilingual commentary to a martyrology, Stam, Typology of Code-switching.

Ter Horst and Stam, Visual diamorphs.

Kämmerer, Codeswitching in Predigten.

www.eva.mpg.de/lingua/resources/glossing-rules.php.

Fletcher, Written versus spoken, 142.

Bériou, Latin and the vernacular, especially appendix 1 and appendix 2, 280-281.

Kamínková, Husova Betlémská kázání.

Schiewer and Schiewer, Opera mixta, e.g., 294. 
present in the majority of multilingual sermons. I argued that the Latin translation was intended for Czech-speaking priests as a preaching aid, as a textual basis for sermons then delivered in Czech. ${ }^{30}$ This particular material allows us to suppose that simple explanations for multilingualism could be misleading: here, a great deal of work was invested to create a Latin translation of a Czech text so the Czech-speaking priests would have a preaching aid. It is something a historian would not expect at first sight.

The newest approach in the study of multilingualism in medieval sermons addresses this issue, taking paleographical aspects of transmitted manuscripts into account. A forerunner in this respect is Laura Wright with her research on business writing. Inspired by the term diamorph that signifies elements that may belong to multiple languages and can work as triggers in the code-switching, she introduced the so-called visual diamorphs, ${ }^{31}$ i.e. letter-graphs or abbreviations that can be expanded in written texts into different languages. Similar to spoken diamorphs in code-switching (so-called homophonous diamorphs), ${ }^{32}$ visual diamorphs may have had a radical influence on code-switching in written texts because of their ambiguity. This new focus on the processes of writing and their effects on code-switching was adopted and further expanded by Tom ter Horst and Nike Stam. ${ }^{33}$ Many sermons, then, can feature both aspects. In an upcoming article, I discuss the role of visual diamorphs in another, curious multilingual adaptation of three sermons from Jan Hus's Czech Sunday postil, in which c. thirteen percent of words were translated into Latin, apparently for no obvious reason. There, I argue that the scribe often chose Latin words in places where the Latin abbreviation was more space effective than the Czech word, which could not be abbreviated in the same way. ${ }^{34}$

This new focus on graphical aspects of code-switching is important insofar as it complements the linguistic methodology developed on contemporary spoken languages by historical dimensions of multilingualism recorded in texts. Tom ter Horst also briefly addresses this issue in this cluster.

The heterogeneity of the material as well as its intricate reception histories preclude any attempt at a "one-size-fits-all« methodological approach. On the contrary, multilingual sermons of the Middle Ages require various and truly interdisciplinary approaches tailored to the specific conditions of individual texts. At the same time, only a broad comparison of multilingual material from various times and areas may give us an understanding of the complexity of present as well as past instances of multilingualism, the respective cultures, societies, and speakers. Philological approaches, studies of rhetoric, sociolinguistic approaches, theories of code-switching and historical contextualization complement each other and enable us to approach the extant sources from various perspectives. We wish to contribute to the productive discussion on the topic and together draw attention to the textual witnesses of medieval multilingualism. 


\section{References}

Azuma, Shoji, Free morpheme constraint revisited, World Englishes 15/3 (1996) 361-367.

Bériou, Nicole, Latin and the vernacular: Some remarks about sermons delivered on Good Friday during the thirteenth century, in: Volker Mertens and Hans-Jochen Schiewer (eds.), Die deutsche Predigt im Mittelalter (Tübingen, 1992) 268-284.

Cenoz, Jasone, Defining multilingualism, Annual Review of Applied Linguistics 33 (2013) 3-18.

Cohen, Thomas V. and Lesley K. Twomey, Introduction, in: Thomas V. Cohen and Lesley K. Twomey (eds.), Spoken Word and Social Practice (Leiden, 2015) 1-44.

D’Avray, David L., The Preaching of the Friars: Sermons Diffused from Paris Before 1300 (Oxford, 1985).

Demo, Šime, Towards a unified definition of macaronics, Humanistica Lovaniensia 63 (2014) 83-106.

Fletcher, Alan J., Written versus spoken macaronic discourse in late medieval England: The view from a pulpit, in: Judith A. Jefferson and Ad Putter (eds.), Multilingualism in Medieval Britain (c. 1066-1520): Sources and Analysis (Turnhout, 2013) 137-152.

Florianová, Hana, Dana Martínková, Zuzana Silagiová and Hana Šedinová (eds.), Quadragesimale Admontense (Prague, 2006).

Halmari, Helena and Timothy Regetz, Syntactic aspects of code-switching in Oxford, MS Bodley 649, in: Herbert Schendl and Laura Wright (eds.), Code-Switching in Early English (Berlin, 2011) 115-154.

Horner, Patrick J., A Macaronic Sermon Collection from Late Medieval England: Oxford, MS Bodley 649 (Toronto, 2006).

Kamínková, Eva, Husova Betlémská kázání a jejich dvě recense (Prague, 1963).

Kämmerer, Carmen, Codeswitching in Predigten des 15. Jahrhunderts: Mittellatein Frühneuhochdeutsch, Mittellatein - Altitalienisch/Altspanisch (Berlin, 2006).

Keller, Mareike L., Code-Switching: Unifying Contemporary and Historical Perspectives (Cham, 2020).

Muysken, Pieter, Bilingual Speech: A Typology of Code-Mixing (Cambridge, 200o).

Myers-Scotton, Carol, Multiple Voices: An Introduction to Bilingualism (Cornwall, 2006).

Odstrčilík, Jan, Translation and transformation of Jan Hus's Czech Sunday postil, in: Pavlína Rychterová and Julian Ecker (eds.), Pursuing a New Order 2 (Turnhout, 2019) 153-184.

Odstrčilík, Jan, Unbearable lightness of multilingual sermons? The so-called Wilhering Adaptation of three Czech sermons of Jan Hus, in: Pavlína Rychterová and Jan Odstrčilík (eds.), Medieval Translations \& Their Readership: Proceedings from the XI Cardiff Conference on the Theory and Practice of Translation in the Middle Ages, The Medieval Translator 18 (Turnhout, forthcoming).

Pfaff, Carol W., Constraints on language mixing: Intrasentential code-switching and borrowing in Spanish/English, Language 55/2 (1979) 291-318.

Poplack, Shana, Sometimes I'll start a sentence in Spanish y termino en español: Toward a typology of code-switching, Linguistics 18/7-8 (1980) 581-618.

Schendl, Herbert, Code-switching in late medieval macaronic sermons, in: Judith A. Jefferson and Ad Putter (eds.), Multilingualism in Medieval Britain (c. 1066-1520): Sources and Analysis (Turnhout, 2013) 153-169. 
Schendl, Herbert, English historical code-switching in a European perspective, in: Christine B. Dabelsteen and J. Normann Jørgensen (eds.), Languaging and Language Practices (Copenhagen, 2004) 188-202.

Schendl, Herbert, Syntactic constraints on code-switching in medieval texts, in: Irma Taavitsainen, Terttu Nevalainen, Päivi Pahta and Matti Rissanen (eds.), Placing Middle English in Context (Berlin, 2000) 67-86.

Schiewer, Hans-Jochen and Regina D. Schiewer, Opera mixta - Deutsch-lateinische Mischpredigten: Überlieferung und Funktion, in: Freimut Löser, Hans-Jochen Schiewer and Regina D. Schiewer (eds.), Meister Eckharts Werk und seine Wirkung: Die Anfänge 11 (Stuttgart, 2017) 291-318.

Stam, Nike, A Typology of Code-switching in the Commentary to the Félire Oengusso (Utrecht, 2017).

Ter Horst, Tom, Codeswitching in the Irish-Latin Leabhar Breac: Mediæval Homiletic Culture (Utrecht, 2017).

Ter Horst, Tom and Nike Stam, Visual diamorphs: The importance of language neutrality in code-switching from medieval Ireland, in: Päivi Pahta, Janne Skaffari and Laura Wright (eds.), Multilingual Practices in Language History: New Perspectives (Berlin, 2018) 223-242.

Wenzel, Siegfried, Macaronic Sermons: Bilingualism and Preaching in Late-Medieval England (Ann Arbor, 1994).

Woolford, Ellen, Bilingual code switching and syntactic theory, Linguistic Inquiry 14/3 (1983) 520-536. 